\title{
Relational schemas as mediators of innovative moments in symptom improvement in major depression
}

\author{
JOÃO BATISTA ${ }^{1}$, JOANA SILVA ${ }^{1}$, SARA FREITAS ${ }^{1}$, DANIELA ALVES ${ }^{1}$, \\ ANABELA MACHADO ${ }^{1}$, INÊS SOUSA ${ }^{2}$, PABLO FERNÁNDEZ-NAVARRO $^{1}$, \\ CARINA MAGALHÃES ${ }^{1}$, \& MIGUEL M. GONÇALVES
}

${ }^{1}$ Psychotherapy and Psychopathology Research Unit, Schoolof Psychology, CIPsi-Psychology Research Center, University of Minho, Braga, Portugal \& ${ }^{2}$ Department of Mathematics, University of Minho, Braga, Portugal

\begin{abstract}
Objectives: Innovative moments (IMs) are exceptions to the maladaptive framework of meaning that typically motivates clients to seek psychotherapy, and previous studies have shown that IMs are associated with psychotherapy outcomes. While IMs are exceptions that occur at the level of the therapeutic conversation, relational schemas are more stable patterns, and their increased flexibility may facilitate change during psychotherapy. With this in mind, we tested the hypothesis that IMs contribute to outcomes by improving the flexibility of relational schemas. Method: The Core Conflictual Relationship Theme (CCRT) was used to assess relational schemas. IMs were evaluated using the Innovative Moments Coding System. The sample included 22 clients diagnosed with major depressive disorder. The flexibility of the three components of the CCRT (Wishes, responses of the self (RS), and responses of others (RO)) were tested as mediators between IMs and outcomes. Results: The flexibility of the RS was a mediator between IMs and outcomes, but Wishes and RO were not. Conclusion: These findings align with previous research showing that RS is the component most open to change, whereas the other components seem less sensitive to change during brief therapy.
\end{abstract}

Keywords: CCRT; innovative moments; process-outcome research; process research; relational schemas

Clinical or methodological significance of this article: This study shows the mediation role of relational schemas in the association between in-session events (innovative moments (IMs)) and the symptoms improvement. It contributes to the literature that emphasizes the importance of relational schemas in psychotherapy by using a mediation model, which has rarely been tested.

The importance of interpersonal factors in psychopathology, and particularly in depression, has been emphasized in psychotherapy research (Hames, Hagan, \& Joiner, 2013; Muran, 2002). However, research involving the rigidity of interpersonal patterns or schemas as an interpersonal factor has revealed mixed results (e.g., McCarthy, Gibbons, \& Barber, 2008; Slonim, Shefler, Dvir Gvirsman, \& Tishby, 2011; Wilczek, Weinryb, Barber, Gustavsson, \& Åsberg, 2004). Studies using measures of interpersonal patterns, such as the Core Conflictual Relationship
Theme (CCRT; Luborsky, 1998a), the Central Relationship Questionnaire (CRQ; Barber, Foltz, \& Weinryb, 1998), or the Quantitative Assessment of Interpersonal Themes (QUAINT; Baranackie \& Crits-Christoph, 1992), have found an association between decreased interpersonal rigidity and successful psychotherapy (e.g., Crits-Christoph \& Luborsky, 1998), whereas others have found no such association (e.g., Lunnen, Ogles, Anderson, \& Barnes, 2006). One study (McCarthy et al., 2008) even found the opposite (and unexpected) association, in which 
greater rigidity was associated with fewer symptoms. Moreover, studies rarely analyze in-therapy processes that might predict changes in relational patterns. An exception in this regard is Grenyer (1996), who studied mastery, defined as the development of selfcontrol and self-understanding in the context of interpersonal relationships. According to Grenyer, an increase in mastery (i.e., self-control and self-understanding) observed in-therapy sessions could explain decreased interpersonal rigidity (Grenyer, 1996; Grenyer \& Luborsky, 1996).

In this research, we followed a similar line of reasoning and studied another in-session measure, IMs (Gonçalves, Ribeiro, Mendes, Matos, \& Santos, 2011), defined as exceptions to the maladaptive framework of meaning that brought the client to therapy. Previous research (e.g., Alves et al., 2014; Gonçalves, Ribeiro, Silva, Mendes, \& Sousa, 2016; Mendes et al., 2010) has shown that IMs are associated with psychotherapy outcomes. In this study, we tested a model in which IMs predict symptom improvement and in which the rigidity of relational patterns mediates this relationship. Thus, we tested whether insession changes (identified by IMs) might foster sufficient changes in interpersonal patterns to significantly contribute, in turn, to symptom recovery.

\section{Innovative Moments}

Gonçalves et al. (2011) developed the concept of IMs, defined as exceptions to the maladaptive framework of meaning that prompted the client to begin psychotherapy (Frank \& Frank, 1991; Gonçalves et al., 2017), based on the notion that this framework of meaning is revised in the therapeutic conversation (and in the client's daily life) as IMs are generated. Thus, IMs are narrative markers of meaning transformation (Gonçalves et al., 2017) that challenge the maladaptive framework and eventually lead to its transformation via psychotherapy.

IMs can be classified into two broad categories (see Gonçalves et al., 2017): Low-level and high-level. Low-level IMs mobilize clients to change by promoting new understandings of the problem, prompting the client to express new feelings and intentions or to develop new actions. These IMs facilitate the client's differentiation from the problematic framework of meaning but do not prompt an alternative framework by themselves. For example, typical depressive clients might see themselves as a failure at everything they do. Low-level IMs occur when such clients gain awareness of this tendency or begin to recognize their daily successes.

By contrast, high-level IMs are centered on change, i.e., on the recognition, elaboration, and expansion of more flexible and satisfactory meanings. These IMs typically take two forms. The first form, contrast, involves recognizing the differences between maladaptive past positions and more adjusted ones, in favor of the latter. The second form, process, involves clients describing the way in which they will be different (e.g., in terms of actions, feelings, and relationships). In the previous example, high-level IMs occur when the clients begin narrating events in which they had coped in a different manner with difficulties in their life (process) or begin describing what is now different from before (contrast). For instance, they may no longer view events as either successes or failures (e.g., "Before, I viewed people as successful or unsuccessful. Of course, I put myself in the latter category. Now, I'm resisting the tendency to classify people like that").

Empirical research employing the Innovative Moments Coding System (IMCS) (Gonçalves et al., 2011) has shown that recovered clients present more IMs than unchanged clients in a variety of psychotherapy models, such as constructivist grief therapy (Alves et al., 2014), client-centered therapy (CCT) (Gonçalves et al., 2012), narrative therapy (NT) (Gonçalves, Ribeiro, et al., 2016), cognitive-behavior therapy (CBT) (Gonçalves, Silva, et al., 2016), and emotion-focused therapy (EFT) (Mendes et al., 2010). Recovered clients have also been shown to present significantly more high-level IMs, while low-level IMs are common in both recovered and unchanged clients (Gonçalves et al., 2017).

\section{Relational Schemas}

Scholars have suggested that humans interpret interpersonal experiences through relational schemas (Leising et al., 2003; Muran, 2002; Žvelc, 2009), which are internalized models of relationships that shape interpretations, behaviors, and expectations during interpersonal encounters (Baldwin, 1992; Muran, 2002). These models represent regularities in patterns of interpersonal relatedness, functioning as cognitive maps that help the person navigate the social world (Baldwin, 1992), deeply affecting the experience of the self in relationships (Žvelc, 2009).

Moreover, representations of important others are laden with affect, having a pervasive role in shaping interpretations and defining emotional responses in most social encounters (Andersen \& Chen, 2002).

Relational schemas are thus considered a core element of the self, deeply influencing interpersonal behavior (Andersen \& Chen, 2002). Given that relational schemas act as subjective rules for interpreting emotionally significant experiences (Demorest, 
Popovska, \& Dabova, 2012), studying such schemas is central to understanding how individuals change over the course of psychotherapy (Demorest, CritsChristoph, Hatch, \& Luborsky, 1999).

In clinical populations, relational schemas are typically overly rigid and recurrent, yielding only a narrow interpretation of relational experiences and thus becoming maladaptive (Dimaggio \& Stiles, 2007; Leising et al., 2003). By contrast, increased flexibility and adaptability of relational schemas has been associated with well-being and with symptom improvement in psychotherapy (e.g., Cierpka et al., 1998; Crits-Christoph \& Luborsky, 1998).

\section{Core Conflictual Relationship Theme}

In our analysis of relational schemas in psychotherapy, we used the CCRT (Luborsky, 1998a). Departing from narratives regarding relationships that clients relate in psychotherapy, the CCRT method identifies recurrent patterns of interpersonal behavior (Luborsky, 1998a). As one of the "most psychometrically sophisticated clinician-based methods forassessing central relationship patterns" (Slonim et al., 2011, p. 686), the CCRT has strong validation (e.g., Crits-Christoph \& Luborsky, 1998).

The CCRT characterizes relational schemas by identifying three components: (i) Wishes, needs, and intentions (W), which refers to the wishes expressed in an interpersonal encounter; (ii) responses of others (RO), which describes the perceived reaction(s) of the other person(s); and (iii) responses of the self (RS), which refers to the person's response to that interaction. The CCRT unit of analysis is the relational episode, i.e., a discrete narration that describes interactions between the client and others, including the self and the therapist (Luborsky, 1998b).

The rigidity of the CCRT has been defined using several measures, including pervasiveness, valence, and dispersion (McCarthy et al., 2008). In this study, we employed dispersion as a measure of CCRT rigidity. Unlike pervasiveness, which measures only the most frequent categories of each component, dispersion measures the component's flexibility by considering all the rated Ws, ROs and RSs in each relational episode (Wilczek et al., 2004). Following authors such as Cierpka et al. (1998), we used a measure of statistical dispersion, derived from the Gini coefficient $C$, that indicates the spread of the distribution of the CCRT components (Cierpka et al., 1998). This measure represents the discrepancy between the observed frequency distribution of each component and the frequency distribution with the maximum amount of spread, given the total number of categories rated in each component (McCarthy et al., 2008). Thus, it is possible to compute the dispersion of each CCRT component by considering its distribution across all relational episodes. Let us consider, as an illustration of the difference between pervasiveness and dispersion, two hypothetical clients with the same $\mathrm{W}$ present in $60 \%$ of all relational episodes, which means that this $\mathrm{W}$ is the most pervasive (i.e., the most frequent). However, one of the hypothetical clients had only one other $\mathrm{W}$ in the remaining relational episodes, whereas the other client had four different Ws. In this imaginary situation, despite having the same pervasiveness, the second client would have a higher dispersion.

Research has shown that the CCRT of more severely impaired clients is characterized by less flexible relational patterns (Cierpka et al., 1998) and more negative RO and RS (Albani et al., 1999). Some studies have validated the association between changes in the CCRT and client improvement in psychotherapy (e.g., Cierpka et al., 1998; Crits-Christoph \& Luborsky, 1998; Slonim et al., 2011). Symptom recovery has been consistently related to increased flexibility regarding CCRT components and a more positive valence in clients who abuse drugs (Ciaglia, 2010), have mood disorders (Crits-Christoph \& Luborsky, 1998), and/or are adolescents (Slonim et al., 2011).

However, as discussed above, other studies (e.g., Lunnen et al., 2006) have failed to find the same associations between decreased CCRT rigidity and symptom improvement. These mixed findings question the assertion that interpersonal rigidity is a determining factor in psychotherapeutic recovery. Two other possible explanations for these mixed results are that the effect of interpersonal rigidity on recovery is small (and thus difficult to identify) and that the relationship between rigidity and change in symptoms might be curvilinear (McCarthy et al., 2008). Finally, the mixed findings were also explained by the use of different methods (e.g., CCRT, QUAINT, or CRQ) and the use of samples with mixed diagnoses. For instance, in Lunnen et al. (2006), the sample consisted of patients with any axis I or axis II disorder.

The role of interpersonal rigidity in recovery is not the subject of broad agreement in the literature. Whereas some authors (Crits-Christoph \& Luborsky, 1998) have considered interpersonal changes to be a curative factor, others (e.g., Wilczek, Weinryb, Barber, Gustavsson, \& Åsberg, 2000) have questioned this assertion, arguing that these changes may be a result of symptom recovery or unrelated phenomena. As discussed above, the notion that interpersonal rigidity might act as a mediator 
between in-session processes and symptom recovery has rarely been studied.

Thus, we tested a model in which relational rigidity, measured by the dispersion of CCRT components, was a mediator between in-session events (IMs) and symptom improvement. This model implies that IMs have a significant impact on the rigidity of the relational schemas, facilitating their revision and that, in turn, the decreased rigidity predicts symptom improvement. Our hypothesis was that IMs (more specifically, high-level IMs) allow clients to develop alternative, more adaptive, interpretations to the maladaptive framework. This alternative framework of meaning can be further developed, becoming a more familiar way of interpreting experiences (and of feeling, behaving, and relating). When this alternative framework of meaning is sufficiently engrained in a client's livingness (in both inner and outer experiences), it may affect deeper structures, such as relational schemas. In other words, we do not expect IMs to have an immediate effect on relational schemas; rather, the changes conveyed in the IMs must be present in the clients' life for a sufficient duration to affect those structures. Thus, this study aimed to test the hypothesis that IMs have an impact on psychotherapy outcomes (as demonstrated by previous studies) by affecting broader and more stable structures, such as relational schemas.

\section{Method}

\section{Sample}

The study sample consisted of 22 clients who were diagnosed with major depressive disorder (MDD) and were being treated by undergoing EFT, NT, or CBT. The maximum number of treatment protocols was 20 sessions (see Greenberg \& Watson, 1998; Lopes et al., 2014 for further details). These subsamples have previously been analyzed using the IMCS: EFT in Mendes et al. (2010), CBT in Gonçalves, Silva, et al. (2016), and NT in Gonçalves, Ribeiro, et al. (2016). No prior analysis using the CCRT has been conducted on these subsamples, and no study has previously associated IMs with the CCRT.

Sample selection. The EFT subsample was taken from the York I Depression Study (Greenberg \& Watson, 1998), which compared the effectiveness of EFT and CCT. Clients had been diagnosed with MDD under the DSM-III-R (American Psychiatric Association, 1987) and based on the Structured Clinical Interviews for DSM-III-R Disorders (SCID) (Spitzer, Williams, Gibbons, \& First, 1989 ). The sample consisted of 34 clients, with 17 in each condition. The clients in this subsample (three recovered and three unchanged) were selected for intensive process analyses that considered the therapy outcome, as measured by the Beck Depression Inventory (BDI) (Beck, Steer, \& Carbin, 1988) cut-off and calculation of a reliable change index (RCI) (Jacobson \& Truax, 1991).

The CBT and NT subsamples were included in a controlled trial that compared their effectiveness (Lopes et al., 2014). Clients were diagnosed with MDD under the DSM-IV-TR (American Psychiatric Association, 2002) and based on the Structured Clinical Interviews for DSM-IV-TR Axis I Disorders (SCID-I) (First, Spitzer, Gibbon, \& Williams, 2002). Considering the BDI-II (Beck, Steer, \& Brown, 1996) cut-off and the RCI for that measure, those who completed the study (20 in each group) were classified as either unchanged or recovered. The current subsamples of 6 CBT clients (three unchanged and three recovered) and $10 \mathrm{NT}$ clients (5 unchanged and 5 recovered) were randomly selected from those who completed the study.

Sample description. The EFT subsample consisted of four women and two men whose ages ranged from 27 to 63 years $(M=45.50, S D=13.78)$. Three of the clients were married, two were divorced and remarried, and one was divorced. One had completed grade 6, two had graduated from high school, and three had enrolled in or graduated from college.

The CBT subsample consisted of five women and one man whose ages ranged from 24 to 46 years $(M=$ $34.50, S D=8.50)$. Two clients were single when they began therapy, three were married, and one was divorced. These clients had between 9 and 16 years of formal education $(M=14.17, S D=2.71)$. Three clients were employed, two were students, and one was unemployed.

The NT subsample consisted of seven women and three men whose ages ranged from 22 to 64 years $(M=41.00, S D=14.97)$. Four clients were single (although one was in a long-term relationship), three were married, two were divorced, and one was widowed. The clients in this subset had between 9 and 24 years of formal education $(M=13.90, S D=$ 5.07). Three were unemployed, three were employed, two were students, and one was retired.

\section{Therapists}

In the EFT subsample, four of the therapists were female and one was male; the therapists had different levels of education, ranging from advanced $\mathrm{PhD}$ students in clinical psychology to $\mathrm{PhD}$ clinical psychologists. The therapists received 24 weeks of training 
(eight weeks covering CCT and the remaining weeks covering experiential techniques) based on a manual devised for the study (Greenberg, Rice, \& Elliott, 1993). Prior to the study, the therapists were supervised with a pilot client. Adherence to the model was rated for four sessions of $20 \mathrm{~min}$ with each client. Session two was always rated, while the other three sessions were randomly selected (see Greenberg \& Watson, 1998 for further details).

The therapist in the CBT subsample was a male $\mathrm{PhD}$ student with 5 years of previous clinical experience. Although he had experience with CBT, he received training from a manual based on the Beck, Rush, Shaw, and Emery (1979) and Leahy and Holland (2000) models of CBT treatments. A more experienced therapist supervised him.

The therapist for the NT subsample was a male $\mathrm{PhD}$ student with 7 years of experience as a psychotherapist. He had 3 years of experience providing NT and received training using a manual based on the White and Epston (1990) model of NT. A more experienced therapist supervised him. To control for therapist preferences, each therapist could choose his or her preferred model (CBT or NT). An adherence scale was applied to four sessions (randomly selected) of each client (CBT and NT) to ensure that the treatments complied with the models (see Lopes et al., 2014 for further details).

\section{Coders}

The IMs were coded by five judges (three females and two males) working in pairs. All the judges were PhD students. The CCRT was coded by five judges (four females and one male) working in pairs. Three of the coders were $\mathrm{PhD}$ students, one was a master's student, and one was a post-doctoral researcher. All the judges had at least 1 year of clinical experience to ensure a minimum of clinical insight in the relational episodes and CCRT coding. One of the judges also coded the IMs in the CBT and NT subsamples.

\section{Treatments}

The protocol used in the EFT subsample departed from the CCT approach of forming an empathic working alliance with added process directive and experiential interventions (Greenberg et al., 1993). This model considers psychological problems asdysfunctions in emotion processing and regulation (Elliott, Watson, Goldman, \& Greenberg, 2004). Therapy is viewed as a tool to help clients access their emotional schemas in a secure environment while striving for more complete and adaptive emotional processing (Greenberg et al., 1993).
The method used in the CBT subsample was based on the treatment protocol for depression developed by Beck et al. (1979). This model maintains that symptoms result from activating negative cognitive schemas, which represent dysfunctional ways of interpreting the self and the world (Beck, 1967). Therapy aims to help clients find new, more adaptive ways of interpreting experiences (Beck, 1967).

The NT intervention manual was developed based on White's work (2007; White \& Epston, 1990). This model posits that psychological problems arise due to unsatisfactory, rigid, and/or problem-saturated life narratives (White \& Epston, 1990). According to White and Epston (1990), not all life events integrate into a life narrative, creating possibilities for new narratives to be constructed by tracking events that occur outside the problematic life story and elaborating upon their meaning.

\section{Measures}

Beck Depression Inventory. The common outcome measure employed in the subsamples was the BDI (BDI, Beck et al., 1988; BDI-II, Beck et al., 1996), which was applied both at pre- and post-test. The BDI-II was used for the CBT and NT subsamples. The BDI was used for the EFT subsample because this sample was collected before the BDI-II was published. The BDI consists of 21 items evaluating depressive symptoms. The items were rated on a four-point Likert scale (0-3), and the total score ranged between 0 and 63 points. Higher BDI and BDI-II values corresponded to greater depressive symptomatology. Clients were considered unchanged if they did not meet the double criteria of the BDI cut-off (11.08 for BDI and 14.29 for BDI-II) and the RCI. Table I presents the range, mean $(M)$ and standard deviation $(S D)$ of the BDI and BDI-II scores at pre- and post-test.

Innovative moments coding system. The IMCS (Gonçalves et al., 2011) is a coding system that divides observed IMs into seven categories, organized into two major groups: Low-level and highlevel IMs. A higher proportion of IMs was associated with a higher presence of alternative experiences to the maladaptive framework of meaning. Moreover, a higher proportion of high-level IMs was associated with narrative innovations that are typical of recovered cases. Studies using the IMCS (e.g., Gonçalves et al., 2012; Mendes et al., 2010) have produced inter-rater agreements ranging between 0.86 and 0.97. Table II presents the proportions of low-level and high-level IMs for the three subsamples, 
Table I. BDI and BDI-II results from the three subsamples.

\begin{tabular}{|c|c|c|c|c|c|c|}
\hline & \multicolumn{3}{|c|}{ Range } & \multicolumn{3}{|c|}{ Mean (standard deviation) } \\
\hline & Pre-test & Post-test (unchanged) & Post-test (recovered) & Pre-test & Post-test (unchanged) & Post-test(recovered) \\
\hline CBT & $16-44$ & $18-34$ & $1-8$ & $30.67(9.14)$ & $25.33(6.60)$ & $4.67(2.87)$ \\
\hline EFT & $15-35$ & $13-22$ & $3-5$ & $25.33(6.18)$ & $17.67(3.68)$ & $4.00(0.82)$ \\
\hline NT & $17-48$ & $20-45$ & $2-7$ & $29.70(9.09)$ & $31.40(8.11)$ & $4.00(2.10)$ \\
\hline
\end{tabular}

Note: EFT results refer to BDI scores; CBT and NT results refer to BDI-II scores.

considering the outcome (clients divided into recovered and unchanged).

Core conflictual relationship theme. The CCRT method (Luborsky, 1998a) was used to assess clients' relational schemas. The CCRT is a content analysis system that identifies relational episodes narrated by the client during therapy and distinguishes the three components (Wishes/Needs, RO, RS) of each relational episode. After the initial coding, the components were converted into standard categories (Table III), as proposed by Barber, Crits-Christoph and Luborsky (1998). A higher pervasiveness, lower dispersion, and negative valence of the components indicated a more rigid and less adaptive relational schema.

\section{Procedures}

IMs identification. The IMs were coded based on the procedures described by Gonçalves et al. (2011, 2017). Prior to the coding, the judges completed a training protocol consisting of (a) a coding manual with a set of excerpts from the dialogues of therapeutic sessions to identify IMs and (b) a full therapeutic case with a series of different coding steps of increasing difficulty. The coding of the IMs consisted of three steps: (i) identification of the maladaptive framework of meaning; (ii) identification of the IM and its beginning and end; and (iii) categorization of the IM.

Table II. Means of IMs proportion in the three subsamples.

\begin{tabular}{llcc}
\hline & & $\begin{array}{c}\text { Low-level IMs } \\
\text { proportion (mean) } \\
(\%)\end{array}$ & $\begin{array}{c}\text { High-level 2 IMs } \\
\text { proportion (mean) } \\
(\%)\end{array}$ \\
\hline \multirow{2}{*}{ CBT } & Recovered & 10.11 & 11.97 \\
& Unchanged & 7.49 & 4.02 \\
EFT & Recovered & 6.39 & 23.95 \\
& Unchanged & 5.53 & 3.38 \\
\multirow{2}{*}{ Total } & Recovered & 9.50 & 15.88 \\
& Unchanged & 9.36 & 8.43 \\
& Recovered & 8.66 & 17.27 \\
& Unchanged & 7.46 & 5.28 \\
\hline
\end{tabular}

Step one consisted of viewing the videos or reading the transcripts of the initial sessions. The judges, working in pairs, reached an agreement regarding the main features of the maladaptive framework of meaning. In the second step, working with the session transcripts, the judges independently identified the IMs in all the psychotherapy sessions. The IMs were defined as exceptions to the maladaptive framework of meaning. The judges identified the beginning and the end of the IMs and their proportions. After the

Table III. Standard categories of the CCRT components (Edition 3).

\begin{tabular}{|c|c|c|}
\hline $\begin{array}{l}\text { CCRT } \\
\text { components }\end{array}$ & & Standard categories (Edition 3) \\
\hline \multicolumn{3}{|l|}{ Wishes } \\
\hline & $\begin{array}{l}1 . \\
2 . \\
3 . \\
4 . \\
5 . \\
6 . \\
7 . \\
8 .\end{array}$ & $\begin{array}{l}\text { To assert self and be independent } \\
\text { To oppose, hurt, and control others } \\
\text { To be controlled, hurt, and not } \\
\text { responsible } \\
\text { To be distant and avoid conflicts } \\
\text { To be close and accepting } \\
\text { To be loved and understood } \\
\text { To feel good and comfortable } \\
\text { To achieve and help others }\end{array}$ \\
\hline \multicolumn{3}{|l|}{$\begin{array}{l}\text { Responses of } \\
\text { Other }\end{array}$} \\
\hline & $\begin{array}{l}1 . \\
2 . \\
3 . \\
4 . \\
5 . \\
6 . \\
7 . \\
8 .\end{array}$ & $\begin{array}{l}\text { Strong } \\
\text { Controlling } \\
\text { Upset } \\
\text { Bad } \\
\text { Rejecting and opposing } \\
\text { Helpful } \\
\text { Likes me } \\
\text { Understanding }\end{array}$ \\
\hline \multicolumn{3}{|c|}{ Responses of Self } \\
\hline & $\begin{array}{l}1 . \\
2 . \\
3 . \\
4 . \\
5 . \\
6 . \\
7 . \\
8 .\end{array}$ & $\begin{array}{l}\text { Helpful } \\
\text { Unreceptive } \\
\text { Respected and accepted } \\
\text { Oppose and hurt others } \\
\text { Self-controlled and self-confident } \\
\text { Helpless } \\
\text { Disappointed and depressed } \\
\text { Anxious and ashamed }\end{array}$ \\
\hline
\end{tabular}

Note: Adapted from Barber, Crits-Christoph, \& Luborsky (1998). 
identification of the IMs in the sessions, eachIM was analyzed to determine its category; this constituted step three. Agreement levels of steps two and three were calculated. When disagreement occurred, a final consensus was reached between the judges with the help of an external auditor with IMCS experience. The judges were unaware of the therapeutic outcomes of the cases.

In the EFT subsample, the main judge coded $100 \%$ of the sessions, and the other judge coded $50 \%$. In the CBT and NT subsamples, both judges coded all the sessions. The IMs were coded prior to this study, between 5 (the EFT subsample) and 2 years previously (NT and CBT subsamples); their coding have been documented in previous studies (Gonçalves, Ribeiro, et al., 2016; Gonçalves, Silva, et al., 2016; Mendes et al., 2010).

The most common measure of IMs is proportion, defined as the length of each IM in the transcript. Thus, the proportion was calculated by dividing the number of words related to each IM by the total number of words in that session. The therapist's statements were also included in the IM due to the co-constructed nature of narrative innovation (Angus, Levitt, \& Hardtke, 1999; Gonçalves et al., 2017).

In previous studies, two reliability indexes were calculated: The percentage of agreement regarding IM identification (step two) and Cohen's $k$ for agreement on the IM category (step three). In the EFT subsample, the agreement on IM identification was $88.7 \%$, and Cohen's $k$ was 0.86 (Mendes et al., 2010). In the CBT subsample, the agreement on IM identification was $90 \%$, and Cohen's $k$ was 0.94 (Gonçalves, Silva, et al., 2016). Finally, in the NT subsample, the agreement on IM identification was 89.9\%, and Cohen's $k$ was 0.91 (Gonçalves, Ribeiro, et al., 2016). All agreements were based on the independent coding of two coders.

CCRT component identification. We used transcripts of the sessions to identify the relational episodes, as proposed by Luborsky (1998b). Two sessions from the beginning of therapy, two from the middle, and two from the end were analyzed. The initial two sessions analyzed were always the second and third sessions; the middle two sessions analyzed were identified arithmetically by dividing the total number of sessions by two; and the final sessions were those immediately prior to the last session. Following Albani et al. (1999), we considered all the relational episodes in the sessions, rather than the minimum of 10 suggested by Luborsky (1998b), which increased the number of narratives used to define the relational schema of each client.
Prior to coding, all the judges completed CCRT training, which included reading the guidelines of Luborsky and Crits-Christoph (1998) and exercises with several clinical sessions. All judges were unaware of the therapeutic outcomes of the cases.

CCRT coding followed the procedures described by Luborsky (1998b) and consisted of three steps: (i) identification of relational episodes in the session transcripts, (ii) identification of the components (W, RO, and RS) of each relational episode, and (iii) assignment of the identified components to a standard category. In the first step, two judges independently identified the relationship episodes in the sessions. After the identification of the relational episodes, the completeness of each episode was rated on a scale from 1 to 5 . This decision was consensual between the judges and had the purpose of avoiding excessive inference in the coding. Thus, only relational episodes with a score of 2.5 or higher were coded. Luborsky (1998b) gives an example of a relational episode with a 2.5 score of completeness: I met Joe, we talked, he said little. He's an old friend from school who I like. I was disappointed he said solittle about the event we went through together. In this example, it is possible to identify the three components (W, RO, and RS).

In the second step, the judges identified the components of each relational episode. In the third step, each identified component was assigned to a standard category (Table III) based on the similarity to one of the categories (e.g., the hypothetical desire to be understood by a spouse would be scored in the $\mathrm{W}$ category "to be understood"). Two reliability indexes were calculated: A percentage of agreement on the identification of relational episodes and an intraclass correlation (ICC) on the identification of the CCRT components. The percent of agreement for the relational episodes was $93.5 \%$. The ICC was 0.89 for W, 0.92 for RO, and 0.93 for RS. These values are high, reflecting adequate agreement.

CCRT dispersion. To calculate the dispersion of each component, we used the dispersion index derived from Gini's concentration measure $C$ (Cierpka et al., 1998). The following formula was used to calculate dispersion (Cierpka et al., 1998):

$$
\begin{aligned}
& \text { Dispersion }= \\
& C=1-\text { Sum of squared relative frequencies } \\
& \text { of codes in each cluster (for } \mathrm{W}, \mathrm{RO} \text { or } \mathrm{RS} \text { ) } \\
& \hline C_{\mathrm{max}}=\text { Maximum value of } C \text { for a given number } \\
& \text { of codes (for } \mathrm{W}, \mathrm{RO} \text { or } \mathrm{RS} \text { ) } \\
& =\frac{C}{C_{\max }} .
\end{aligned}
$$


Table IV. CCRT components dispersion.

\begin{tabular}{llccc}
\hline Cishes & $\begin{array}{c}\text { Responses of } \\
\text { other } \\
\text { dispersion }\end{array}$ & $\begin{array}{c}\text { Responses of } \\
\text { the self- } \\
\text { dispersion }\end{array}$ \\
\hline CBT & Recovered & 0.77 & 0.81 & 0.84 \\
EFT & Unchanged & 0.74 & 0.63 & 0.64 \\
NTT & Uncovered & 0.85 & 0.78 & 0.89 \\
& Recovered & 0.78 & 0.68 & 0.71 \\
Total & Unchanged & 0.62 & 0.34 & 0.79 \\
& Recovered & 0.80 & 0.74 & 0.52 \\
& Unchanged & 0.72 & 0.55 & 0.84 \\
\hline
\end{tabular}

Computation of the maximum value of $C\left(C_{\max }\right)$ for a given number of codes (for $\mathrm{W}, \mathrm{RO}$, or RS) followed the formulas described by Cierpka et al. (1998). The discrepancy between the observed and maximum spread distributions represented the level of dispersion of the CCRT component (McCarthy et al., 2008). According to Cierpka et al. (1998), the higher the dispersion score, the more flexible the relational pattern is, whereas lower scores indicate that the pattern is highly rigid. The Gini dispersion index $(C)$ varied between 0 (maximum rigidity) and 1 (lowest rigidity). Table IV presents the mean of the dispersion of the three subsamples. The clients were divided into recovered and unchanged.

Mediation model. We opted for the Baron and Kenny (1986) method to test the mediation model, although we accounted for more recent developments in mediation analysis (Frazier, Tix, \& Barron, 2004; MacKinnon, Fairchild, \& Fritz, 2007; Mallinckrodt, Abraham, Wei, \& Russell, 2006). There are three ways to test a mediation effect: Causal steps, difference in coefficients, and product of coefficients. We followed the causal steps method, the most common model in mediation analysis, in which four conditions are required to confirm the mediation (MacKinnon et al., 2007).

The first step is to determine the existence of a significant relation between the independent variable and the dependent variable. The independent variable was the mean of the IM proportion of all the sessions for each client. We studied two different models of mediation, one for low-level IMs and one for high-level IMs. The therapeutic outcome (dependent variable) measure was the difference between the post-test and pre-test BDI scores $(\triangle \mathrm{BDI}=$ posttest - pre-test). This relation is expected to be negative (the higher is the mean of the IMs, the lower is the difference between post-test and pre-test), as a negative difference between post- and pre-test indicates lower symptomatology at the end of therapy.
The second step is to determine the existence of a significant relation between the independent variable and the hypothesized mediator, i.e., the dispersion of the CCRT components in the last phase of psychotherapy. As referred, it is not plausible to assume that relational schemas would change early in psychotherapy. Thus, we decided to use only the CCRT dispersion of the final sessions. Another reason for excluding the initial and intermediate CCRT measurement was the temporal sequence of mediation. This association is expected to be positive, as the higher is the mean of the IMs, the higher is the dispersion (i.e., flexibility) of the CCRT components at the end of psychotherapy.

The third step is to determine the existence of a significant association between the mediator (CCRT dispersion) and the dependent variable (BDI scores). This association is expected to be negative because a higher dispersion of the CCRT components has been associated with lower symptom severity (Cierpka et al., 1998). The fourth step is to determine that the coefficient relating the independent variable to the dependent variable is lower (or not significant) in the regression model, using both the independent variable and the mediator as predictors, compared to the coefficient of the regression model without the mediator. In other words, in the regression model with the mediator (the CCRT dispersion), it is expected that the independent variable direct path will have a lower coefficient or will not be a significant predictor. A mediation effect exists if the indirect path is also significant.

\section{Results}

\section{Mediation Model}

As discussed above, the test of the mediation model followed the four steps proposed by Baron and Kenny (1986). In the first step, the association between the means of the IMs and the change in the BDI scores was tested. The mean of low-level IMs was not a significant predictor of the change in BDI scores, whereas the mean of high-level IMs was a significant predictor $\left(R_{\mathrm{dj}}^{2}=426 ; p=.001\right)$. As expected, the association was negative, indicating that a higher proportion of high-level IMs was associated with a greater decrease in the BDI score from pre-to post-test. Given that low-level IMs were not a predictor of symptom change, the following analyses included only high-level IMs.

The second stage of the analysis tested the association between the mean of high-level IMs and the dispersion of the CCRT components. The mean of high-level IMs was not a significant predictor of $\mathrm{W}$ or RO but was a significant predictor of RS, for 
which a significant association was found $\left(R_{\mathrm{adj}}^{2}=.266 ; p=.01\right)$. The association was positive, indicating that the higher was the proportion of IMs, the higher was the RS dispersion. Thus, a higher proportion of high-level IMs predicted a less rigid RS component.

Step three of the mediation model implies that the mediator is a significant predictor of the dependent variable. Therefore, we tested the dispersion of $\mathrm{W}$, RO, and RS (the CCRT components) as predictors of BDI scores. Neither the dispersion of $\mathrm{W}$ nor that of RO was a significant predictor of BDI scores. Therefore, these CCRT components were removed from the mediation model. The dispersion of the RS component was a significant predictor of BDI scores $\left(R_{\mathrm{adj}}^{2}=489 ; p=.0002\right)$ and was thus included in the mediation model.

In step four, a regression model was tested that used the mean of high-level IMs and the dispersion of RS as predictor of the BDI scores. As discussed above, the mediating effect is confirmed if the previous association between the independent variable (the IMs) and the dependent variable (the BDI score) is weakened or becomes non-significant after the mediator is removed from the model. The results of the model were as expected.

In fact, the association of the high-level IMs with the BDI scores became less significant $(p=.01)$. Concurrently, the association in the indirect path was a significant predictor of the BDI scores $\left(R_{\mathrm{adj}}^{2}=.600 ; p=.006\right)$. Thus, the direct path between IMs and BDI scores became less significant, whereas the indirect path association (which considers the mediating effect of the RS component) was significant, confirming partial mediation by that component.

\section{Discussion}

This study tested a mediation model in which the impact of in-session events (IMs) on psychotherapeutic recovery is mediated by the change in the rigidity of relational schemas, as measured by the CCRT. Despite the theoretical assumption that psychotherapy should be associated with a decrease in the rigidity of relational schemas, previous findings have been mixed, and some studies have failed to find such an association. In attempting to replicate these studies in which the rigidity of the relational schemas predicted outcomes, we tested a mediation model employing IMs as the independent variable. Moreover, we opted to use dispersion as a measure of rigidity, given the limitation of the use of pervasiveness as such. Pervasiveness is a measure based on the psychodynamic notion that there is a central relational pattern that repeats itself (Luborsky, 1998a); therein, it considers only the most frequent category of each CCRT component. On the other hand, dispersion allows for a more encompassing approach by considering all the categories.

The results of the model supported the mediating role of the interpersonal rigidity of the RS component. RS was the only component showing a significant association with symptom recovery, as measured with the BDI. This result supports the assertion of Crits-Christoph and Luborsky (1998) that this component of the CCRT is the most open to change in psychotherapy and is more sensitive to brief psychotherapy. This result also supports the idea that interpersonal rigidity may not change substantially after successful brief psychotherapy, considering that neither the $\mathrm{W}$ nor the RO component was associated with symptom recovery. However, the mediating role of RS was only partial, which can be explained by the existence of other factors, in addition to relational schemas, that influence the association between IMs and psychotherapeutic change. This result accords with the assumption that it is difficult in psychology to find a complete moderation effect (Judd \& Kenny, 1981). In fact, other variables may be present in this mediation, such as symptom severity, ambivalence towards change (Ribeiro et al., 2014), or readiness for change, among others. Moreover, and according to Kazdin (2009), a mediator suggests critical processes about why change occurs, although it may not be a mechanism of change by itself.

The results of the mediation model of RS supported only this role for high-level IMs. This is consistent with previous studies in which low-level IMs were not significant predictors of symptom measures. High-level IMs were the primary predictors of outcomes in previous research. Our results reinforce the notion that the processes involved in high-level IMs can be viewed as either facilitators or mechanisms of change in psychotherapy. As discussed above, the mechanisms by which relational schemas change have not been addressed particularly frequently in psychotherapy research. Grenyer and Luborsky (1996) proposed that these changes result from an increase in clients' sense of mastery, defined as emotional self-control and self-understanding (Grenyer, 1996).

Changes in clients' relational schemas have also been explained by the development of a more flexible and integrated view of the self and others. In previous studies using the IM framework (e.g., Alves et al., 2014; Gonçalves, Ribeiro, et al., 2016; Mendes et al., 2011), high-level IMs were associated with clients' ability to elaborate upon and develop different views of themselves. High-level IMs are primarily 
adaptive contrasts (in which clients identify what changed from their perspective), processes of change, or strategies associated with improvement (in which clients elaborate upon how or why they changed). By tracking contrasts between the maladaptive framework of meaning and alternative frameworks or by emphasizing the ways in which change has been achieved, high-level IMs foster both adaptive change and a sense of self-continuity (Cunha, Gonçalves, Valsiner, Mendes, \& Ribeiro, 2012; Gonçalves \& Ribeiro, 2012), allowing the more adaptive forms of functioning to be integrated into the client's self-narratives. Additionally, identifying the strategies and processes that the client associates with his or her changes promotes the client's access to a self-observing, metacognitive perspective associated with self-understanding and recovery through psychotherapy (e.g., Dimaggio \& Stiles, 2007). Moreover, high-level IMs are also expressions of a with recovery in various psychotherapy models (Williams \& Levitt, 2007). High-level IMs can thus be understood as a set of alternative meanings contributing to a more flexible way of relating to others and to recovery in psychotherapy.

Another important contribution of this study is its support for the association between two measures of narrative change (IMs and CCRT), as well as their relevance for symptom change. Although both IMs and CCRT are narrative measures, they have different theoretical backgrounds (psychodynamic therapy versus NT) and involve different procedures. Their relationship is further support for the convergent validity of the IMs.

A methodological limitation of this study is that the BDI was used as the outcome measure for one subsample, whereas the BDI-II was used as the measure for the other two subsamples, potentially threatening internal validity. Another methodological limitation is the extraction of the CCRT from sessions that were also coded with the IMs. Although this happened in only two sessions out of an average of 17.7, considering that only the CCRT from the final sessions was analyzed, it may nonetheless limit the independence of the two measurements. The coding of the IMs with two different procedures (one subsample with $50 \%$ independent coding and the other with $100 \%$ independent coding) is also a limitation.

The difference in the number of therapists providing treatment in the subsamples can also be considered a limitation: One therapist provided treatment in the CBT and NT subsamples, whereas the EFT sample included five therapists. Moreover, the EFT therapist had formation before the clinical trial, whereas the therapists in the CBT and TN subsamples had supervision throughout the trial.
However, neither the formation nor the supervision was focused on the change in relational schemas or the generation of IMs. In this sense, we consider this issue to not have influenced the study results. Another limitation is the sample size. Given the small size of the sample, the generalizability of the results is limited. Despite the association between variables supported by this study, these relationships do not prove causality. Nonetheless, the associations identified in this study are congruent with theoretical expectations.

Finally, the mechanisms of change identified by the

IMs are similar to those found to be therapeutic by other studies and authors (Badgio, Halperin, \& Barber, 1999; Dimaggio, Hermans, \& Lysaker, 2010; Grenyer \& Luborsky, 1996). Therefore, we may hypothesize that IMs are mechanisms that foster change in broader, more stable structures (such as relational schemas), significantly contributing to symptom recovery.

\section{Acknowledgments}

The authors are very grateful to Dr Paul Crits-Christoph for assisting us in the coding of the CCRT. They are also very grateful to Dr Leslie Greenberg and Dr Lynne Angus for allowing us to use the York I sample.

\section{Funding}

This study was conducted at Psychology Research Center (UID/PSI/01662/2013), University of Minho, and supported by the Portuguese Foundation for Science and Technology (FCT) and the Portuguese Ministry of Science, Technology and Higher Education through national funds and co-financed by FEDER through COMPETE2020 under the PT2020 Partnership Agreement (POCI-01-0145FEDER-007653). The Portuguese Foundation for Science and Technology also supported this study through the PhD Grant SFRH/BD/77324/2011.Fundação para a Ciência e a Tecnologia

\section{References}

Albani, C., Benninghofen, D., Blaser, G., Cierpka, M., Dahlbender, R., Geyer, M., ... Kächele, H. (1999). On the connection between affective evaluation of recollected relationship experiences and the severity of the psychic impairment. 
Psychotherapy Research, 9(4), 452-467. doi:10.1080/ 10503309912331332861

Alves, D., Fernández-Navarro, P., Baptista, J., Ribeiro, E., Sousa, I., \& Gonçalves, M. M. (2014). Innovative moments in grief therapy: The meaning reconstruction approach and the processes of self-narrative transformation. Psychotherapy Research, 24(1), 25-41. doi:10.1080/10503307.2013.814927

American Psychiatric Association. (1987). Diagnostic and statistical manual of mental disorders (3rd ed.), revised (DSM-III-R). Washington, DC: American Psychiatric Association.

American Psychiatric Association. (2002). DSM-IV-TR: Manual de diagnóstico e estatística das perturbações mentais [DSM-IVTR: Diagnostic and statistical manual of mental disorders] (4th ed.). Lisboa: Climepsi Editores.

Andersen, S. M., \& Chen, S. (2002). The relational self: An interpersonal social-cognitive theory. Psychological Review, 109(4), 619-645. doi:10.1037/0033-295X.109.4.619

Angus, L., Levitt, H., \& Hardtke, K. (1999). The narrative processes coding system: Research applications and implications for psychotherapy practice. Journal of Clinical Psychology, 55 (10), 1255-1270. doi:10.1002/(SICI) 1097-4679 (199910)55:10<1255::AID-JCLP7>3.0.CO;2-F

Badgio, P. C., Halperin, G. S., \& Barber, J. P. (1999). Acquisition of adaptive skills: Psychotherapeutic change in cognitive and dynamic therapies. Clinical Psychology Review, 19(6), 721-737. doi:10.1016/S0272-7358(98)00081-6

Baldwin, M. (1992). Relational schemas and the processing of social information. Psychological Bulletin, 112(3), 461-484. doi:10.1037/0033-2909.112.3.461

Baranackie, K., \& Crits-Christoph, P. (1992). The quantitative assessment of inter-personal themes (QUAINT) rater manual. University of Pennsylvania. Unpublished manuscript.

Barber, J. P., Crits-Christoph, P., \& Luborsky, L. (1998). A guide to CCRT standard categories and their classification. In L. Luborsky \& P. Crits-Christoph (Eds.), Understanding transfer-ence: The core conflictual relationship theme method (2nd ed., pp. 43-54).

Washington, DC: American Psychological Association. Barber, J. P., Foltz, C., \& Weinryb, R. M. (1998). The central relationship questionnaire: Initial report. Journal of Counseling Psychology, 45(2), 131-142. doi:10.1037/0022-0167.45.2.131

Baron, R. M., \& Kenny, D. A. (1986). The moderator-mediator variable distinction in social psychological research: Conceptual, strategic, and statistical considerations. Journal of Personality and Social Psychology, 51(6), 1173-1182. doi:10. 1037/0022-3514.51.6.1173

Beck,A.T.(1967).Depression: Clinical, experimental, and theoretical aspects. Philadelphia, PA: University of Pennsylvania Press.

Beck, A. T., Rush, A. J., Shaw, B. F., \& Emery, G. (1979). Cognitive therapy of depression. New York, NY: Guilford Press.

Beck, A. T., Steer, R. A., \& Brown, G. K. (1996). Manual for Beck Depression Inventory II. San Antonio, TX: Psychological Corporation.

Beck, A. T., Steer, R. A., \& Carbin, M. G. (1988). Psychometric properties of the Beck Depression Inventory: Twenty-five years of evaluation. Clinical Psychology Review, 8(1), 77-100. doi:10.1016/0272-7358(88)90050-5

Ciaglia,D.(2010). Thepsychotherapy of drug dependence: Changesin core conflictual relationship themes (Doctoral dissertation). University of Wollongong. Retrieved from http://ro.uow.edu. au/theses/3206

Cierpka, M., Strack, M., Benninghoven, D., Staats, H., Dahlbender, R., Pokorny, D., ... Albani, C. (1998). Stereotypical relationship patterns and psychopathology. Psychotherapy and Psychosomatics, 67(4/5), 241-248. doi:10. $1159 / 000012286$

Crits-Christoph, P., \& Luborsky, L. (1998). Changes in CCRT pervasiveness during psychotherapy. In L. Luborsky \& P.
Crits-Christoph (Eds.), Understanding transference: The core conflictual relationship theme method (2nd ed., pp. 151-163). Washington, DC: American Psychological Association.

Cunha, C., Gonçalves, M. M., Valsiner, J., Mendes, I., \& Ribeiro, A. P. (2012). Rehearsing renewal of identity: Reconceptualization on the move. In M. C. Bertau, M. M. Gonçalves, \& P. Raggat (Eds.), Dialogic formations: Investigations into the origins and development of the dialogical self (pp. 205-233). Charlotte, NC: Information Age.

Demorest, A. P., Crits-Christoph, P., Hatch, M., \& Luborsky, L. (1999). A comparison of interpersonal scripts in clinically depressed versus nondepressed individuals. Journal of Research in Personality, 33(3), 265-280. doi:10.1006/jrpe.1999.2246

Demorest, A., Popovska, A., \& Dabova, M. (2012). The role of scripts in personal consistency and individual differences. Journal of Personality, 8o(1), 187-218. doi:10.1111/j.14676494.2011.00727.x

Dimaggio, G., Hermans, H. J., \& Lysaker, P. H. (2010). Health and adaptation in a multiple self: The role of absence of dialogue and poor metacognition in clinical populations. Theory \& Psychology, 2O(3), 379-399. doi:10.1177/0959354310363319

Dimaggio, G., \& Stiles, W. B. (2007). Psychotherapy in light of internal multiplicity. Journal of Clinical Psychology, 63(2), 119127. doi:10.1002/jclp. 20335

Elliott, R., Watson, J. C., Goldman, R. N., \& Greenberg, L. S. (2004). Learning emotion-focused therapy: The process-experiential approach to change. Washington, DC: American Psychological Association.

First, M. B., Spitzer, R. L., Gibbon, M., \& Williams, J. B. W. (2002). Structured clinical interview for DSM-IV-TR axis I disorders, research version, non-patient edition (SCID-I/NP). New York, NY: New York State Psychiatric Institute, Biometrics Research.

Frank, J.D., \& Frank, J. (1991). Persuasion and healing: A comparative study of psychotherapy (3rd ed.). Baltimore, MD: Johns Hopkins University Press.

Frazier, P. A., Tix, A. P., \& Barron, K. E. (2004). Testing moderator and mediator effects in counseling psychology research. Journal of Counseling Psychology, 51(1), 115-134. doi:10.1037/ 0022-0167.51.1.115

Gonçalves, M. M., Mendes, I., Cruz, G., Ribeiro, A., Sousa, I., Angus, L., \& Greenberg, L. (2012). Innovative moments and change in client-centered therapy. Psychotherapy Research, 22 (4), 389-401. doi:10.1080/10503307.2012.662605

Gonçalves, M. M., \& Ribeiro, A. P. (2012). Therapeutic change, innovative moments, and the reconceptualization of the self: A dialogical account. International Journal for Dialogical Science, 6(1), 81-98. Retrieved from http://hdl.handle.net/ $1822 / 20928$

Gonçalves, M. M., Ribeiro, A. P., Mendes, I., Alves, D., Silva, J., Rosa, X., ... Oliveira, J. T. (2017). Three narrative-based coding systems: Innovative moments, ambivalence and ambivalence resolution. Psychotherapy Research, 27(3), 1-13. doi:10. 1080/10503307.2016.1247216

Gonçalves, M. M., Ribeiro, A. P., Mendes, I., Matos, M., \& Santos, A. (2011). Tracking novelties in psychotherapy process research: The innovative moments coding system. Psychotherapy Research, 21(5), 497-509. doi:10.1080/ 10503307.2011.560207

Gonçalves, M. M., Ribeiro, A. P., Silva, J. R., Mendes, I., \& Sousa, I. (2016). Narrative innovations predict symptom improvement: Studying innovative moments in narrative therapy of depression. Psychotherapy Research, 26(4), 425-435. doi:10.1080/10503307.2015.1035355

Gonçalves, M. M., Silva, J. R., Mendes, I., Rosa, C., Ribeiro, A. P., Batista, J., ... Fernandes, C. F. (2016). Narrative changes predict a decrease in symptoms in CBT for depression: An 
exploratory study. Clinical Psychology \& Psychotherapy. doi:10. 1002/cpp. 2048

Greenberg, L. S., Rice, L. N., \& Elliott, R. (1993). Facilitating emotional change: The moment-by-moment process. New York, NY: Guilford Press.

Greenberg, L. S., \& Watson, J. (1998). Experiential therapy of depression: Differential effects of client-centred relationship conditions and process interventions. Psychotherapy Research, 8 (2), 210-224. doi:10.1080/10503309812331332317

Grenyer,B.F.(1996). Mastery throughpsychotherapy (Doctoraldissertation). University of Wollongong. Retrieved from http://ro. uow.edu.au/theses/1667.

Grenyer, B. F., \& Luborsky, L. (1996). Dynamic change in psychotherapy: Mastery of interpersonal conflicts. Journal of Consulting and Clinical Psychology, 64(2), 411-416. doi:10. 1037/0022-006X.64.2.411

Hames, J. L., Hagan, C. R., \& Joiner, T. E. (2013). Interpersonal processes in depression. Annual Review of Clinical Psychology, 9 (1), 355-377. doi:10.1146/annurev-clinpsy-050212-185553

Jacobson, N. S., \& Truax, P. (1991). Clinical significance: A statistical approach to defining meaningful change in psychotherapy research.JournalofConsulting and Clinical Psychology,59(1), 1219. doi:10.1037/0022-006X.59.1.12

Judd, C. M., \& Kenny, D. A. (1981). Estimating the effects of social interventions. Cambridge: Cambridge University Press.

Kazdin, A. E. (2009). Understanding how and why psychotherapy leads to change. Psychotherapy Research, 19(4-5), 418-428. doi:10.1080/10503300802448899

Leahy, R. L., \& Holland, S. J. (2000). Treatment plans and interventions for depression and anxiety disorders. New York, NY: The Guilford Press

Leising, D., Rudolf, G., Stadler, K., Jakobsen, T., Oberbracht, C., \& Grande, T. (2003). Do interpersonal behavior and emotional experience change in the course of successful long-termpsychoanalytic therapies? Psychotherapy Research, 13(4), 461-474. doi:10.1093/ptr/kpg037

Lopes, R. T., Gonçalves, M. M., Machado, P. P., Sinai, D., Bento, T., \& Salgado, J. (2014). Narrative therapy vs. cognitive-behavioral therapy for moderate depression: Empirical evidence from a controlled clinical trial. Psychotherapy Research, 24(6), 662674. doi:10.1080/10503307.2013.874052

Luborsky, L. (1998a). The early life of the idea for the core conflictual relationship theme method. In L. Luborsky \& P. CritsChristoph (Eds.), Understanding transference: The core conflictual relationship theme method (2nd ed., pp. 3-13). Washington, DC: American Psychological Association.

Luborsky, L. (1998b). A guide to the CCRT method. In L. Luborsky \& P. Crits-Christoph (Eds.), Understanding transference: The core conflictual relationship theme method (2nd ed.,pp.

15-42). Washington, DC: American Psychological Association.

Luborsky, L., \& Crits-Christoph, P. (1998). Understanding transference: The core conflictual relationship theme method. Washington, DC: American Psychological Association.

Lunnen, K. M., Ogles, B. M., Anderson, T. M., \& Barnes, D. L. (2006). A comparison of CCRT pervasiveness and symptomatic improvement in brief therapy. Psychology and Psychotherapy: Theory, Research and Practice, 79(2), 289-302. doi:10.1348/ $147608305 \times 53206$
MacKinnon, D. P., Fairchild, A. J., \& Fritz, M. S. (2007). Mediation analysis. Annual Review Psychology, 58, 593-614. doi:10.1146/annurev.psych.58.110405.085542

Mallinckrodt, B., Abraham, W. T., Wei, M., \& Russell, D. W. (2006). Advances in testing the statistical significance of mediation effects. Journal of Counseling Psychology, 53(3), 372378. doi:10.1037/0022-0167.53.3.372

McCarthy, K. S., Gibbons, M. B., \& Barber, J. P. (2008). The relation of rigidity across relationships with symptoms and functioning: An investigation with the revised central relationship questionnaire. Journal of Counselling Psychology, 55(3), 346358. doi:10.1037/a0012578

Mendes, I., Ribeiro, A. P., Angus, L. E., Greenberg, L. S., Sousa , I., \& Gonçalves, M. M. (2010). Narrative change in emotionfocused therapy: How is change constructed through the lens of the innovative moments coding system. Psychotherapy Research, 2O(6), 692-701. doi:10.1080/10503307.2010.514960

Mendes, I., Ribeiro, A. P., Angus, L., Greenberg, L. S., Sousa, I., \& Gonçalves, M. M. (2011). Narrative change in emotionfocused psychotherapy: A study on the evolution of reflection and protest innovative moments. Psychotherapy Research,21 (3), 304-315. doi:10.1080/10503307.2011.565489

Muran, J. C. (2002). A relational approach to understanding change: Plurality and contextualism in a psychotherapy research program. Psychotherapy Research, 12(2), 113-138. doi:10.1080/ 713664276

Ribeiro, A. P., Mendes, I., Stiles, W. B., Angus, L., Sousa, I., \& Gonçalves, M. M. (2014). Ambivalence in emotion-focused therapy for depression: The maintenance of problematically dominant self-narratives. Psychotherapy Research, 24(6), 702710. doi:10.1080/10503307.2013.879620

Slonim, D. A., Shefler, G., Dvir Gvirsman, S., \& Tishby, O. (2011). Changes in rigidity and symptoms among adolescents in psychodynamic psychotherapy. Psychotherapy Research, 21 (6), 685-697. doi:10.1080/10503307.2011.602753

Spitzer, R., Williams, J., Gibbons, M., \& First, M. (1989) Structured clinical interview for DSM-III-R. New York, NY: American Psychiatric Press.

White, M. (2007). Maps of narrative practice. New York, NY: WW Norton \& Company.

White, M., \& Epston, D. (1990). Narrative means to therapeutic ends. New York, NY: Norton.

Wilczek, A., Weinryb, R., Barber, J., Gustavsson, J. P., \& Åsberg, M. (2000). The core conflictual relationship theme (CCRT) and psychopathology in patients selected for dynamic psychotherapy. Psychotherapy Research, 10(1), 100-113. doi:10. 1093/ptr/10.1.100

Wilczek, A., Weinryb, R. M., Barber, J. P., Gustavsson, J. P., \& Åsberg, M. (2004). Change in the core conflictual relationship theme after long-term dynamic psychotherapy. Psychotherapy Research, 14(1), 107-125. doi:10.1093/ptr/kph007

Williams, D. C., \& Levitt, H. M. (2007). Principles for facilitating agency in psychotherapy. Psychotherapy Research, 17(1), 66-82. doi: $10.1080 / 10503300500469098$

Žvelc, G. (2009). Between self and others: Relational schemas as an integrating construct in psychotherapy. Transactional Analysis Journal, 39(1), 22-38. doi:10.1177/ 036215370903900104 